\title{
Alleviating effects of silicon on cadmium toxicity in ginger (Zingiber officinale Roscoe)
}

\author{
Zijing Chen ( $\square$ chenzijing@sdau.edu.cn ) \\ ShanDong Agricultural University \\ Jing Zhang \\ Shandong Agricultural University \\ Kun Xu \\ Shandong Agricultural University \\ Bili Cao \\ ShanDong Agricultural University
}

\section{Research article}

Keywords: ginger, cadmium stress, silicon, photosynthesis, antioxidant activity

Posted Date: January 29th, 2020

DOI: https://doi.org/10.21203/rs.2.22203/v1

License: (c) (1) This work is licensed under a Creative Commons Attribution 4.0 International License. Read Full License 


\section{Abstract}

Background: This study assessed the effects of varying concentrations of silicon ( $\mathrm{Si}$ ) on the reduction of cadmium ( $2 \mathrm{mg} / \mathrm{kg} \mathrm{Cd}$ ) toxicity in Zingiber officinale Rosc. via growth modulation, photosynthetic efficiency, and antioxidant defense.

Result: As the Cd level increased, the physiological indexes of ginger exhibited a decreasing trend. This trend was especially noticeable when the Cd level was $2 \mathrm{mg} / \mathrm{kg}$. Next, the effect of different content of soil conditioner Si on ginger under $2 \mathrm{mg} / \mathrm{kg} \mathrm{Cd}$ soil background was explored. This effect was assessed under $2 \mathrm{mg} / \mathrm{kg}$ Cd soil background. The three treatment SiO (0), Si1 (1 g/ kg), Si2 (2g/kg) were examined. Morphology indexes, $\mathrm{Cd}$ content, $\mathrm{Cd}$ transfer and absorption coefficient, photosynthesis, and antioxidant enzyme activities under $\mathrm{Cd}$ stress were determined. On day 120 of the experiment, plant height had increased by $18.8 \%$ and $24.7 \%$ under the Si 1 and $\mathrm{Si} 2$ treatments compared with the CK treatment. Meanwhile, the fresh weight of the rhizomes in Si1 and Si2 had increased by $14.3 \%$ and $19.5 \%$ in comparison with the Si0 treatment. Also, the yield of ginger improved dramatically under the Si1 and Si2 treatments. These treatments had increased by $14.3 \%$ and $19.5 \%$ compared with the CK treatment. The growth of ginger increased after the addition of $\mathrm{Si}$ under $\mathrm{Cd}$ stress, especially under the $\mathrm{Si} 2$ treatment. The $\mathrm{Cd}$ content of the mother-ginger, son-ginger, and grandson-ginger decreased by $27.6 \%, 35.5 \%$, and $51.2 \%$, respectively, under $2 \mathrm{mg} / \mathrm{kg}$ Cd stress in the $\mathrm{Si} 2$ treatment. The Cd transfer was inhibited from the underground to the aboveground in the high-concentration Si treatment (Si2). When $1 \mathrm{~g} / \mathrm{kg}$ and $2 \mathrm{~g} / \mathrm{kg} \mathrm{Si}$ was added to the soil, the leaf photosynthetic rate increased by $15.1 \%$ and $26.9 \%$ compared with the CK treatment at 11:00, respectively.

Conclusion : Above all, soil conditioner Si could alleviate the negative effects of $\mathrm{Cd}$ stress on ginger by improving growth parameters, photosynthetic efficiency and the anti-oxidative defense. Si2 $(2 \mathrm{~g} / \mathrm{kg}) \mathrm{was}$ the most effective.

\section{Background}

Cadmium (Cd) is one of the most poisonous heavy metals and widespread environmental pollutants [1]. The concentration of $\mathrm{Cd}$ in soil has been increasing in recent years. It is ranked as number seven among the top 20 toxins [2]. Its absorption coefficient is higher compared with other heavy metals such as copper and zinc. Absorption of $\mathrm{Cd}$ relies on the $\mathrm{Cd}$ concentration in soil [3]. As a result of industrial wastewater, exhaust emissions, and inappropriate use of pesticides and fertilizers, Cd pollution in the soil has become increasingly common. It thus poses a serious health risk to humans. Cd can immobilize in soil by binding to organic matter, and it is easily taken up and accumulated by plants [4]. Thus, dietary intake of the biotoxic crops could be a severe threat to humans, and the most likely risk is chronic toxicity in humans [5]. Besides being carcinogenic, $\mathrm{Cd}$ inhalations could harm the lungs, liver, kidneys, and bones [6]. In taller plants, Cd could accumulate in any part of the plant since it is highly mobile in phloem tissue. Cd toxicity changes chloroplast ultrastructure, decreases the net photosynthetic rate, leaf transpiration, 
and stomatal conductance [7]. Cd toxicity is usually accompanied by oxidative stress and DNA breakdown [8] and, ultimately, causes cellular damage or apoptosis $[9,10]$.

Recent studies indicate that a variety of strategies have been developed to lessen the toxic effects of $\mathrm{Cd}$ pollution. Nitric oxide (NO), as a signaling molecule, has a pivotal role in plant resistance to various stresses, including heavy metal stresses, such as Cd [11]. NO could interact with ROS, especially $\mathrm{O}^{2-}$, because of the presence of an unpaired e- within the NO molecule [12]. NO improved tolerance to $\mathrm{Cd}$ toxicity by reducing oxidative stress that is considered as the leading cause of cell death [13]. In Lupinus, when roots were grown in $50 \mu \mathrm{M} \mathrm{Cd}$, NO could stimulate SOD activity to counteract the overproduction of $\mathrm{O}^{2-}$ [14]. One study found that salicylic acid alleviates Cd-induced photosynthetic damage and cell death by inhibiting reactive oxygen overproduction [15]. The improvement of signal transduction also increased plant tolerance to $\mathrm{Cd}$, and decreased cell death resulted from $\mathrm{Cd}[10,16]$. The soil amendment, Biochar, has been known to protect plants against heavy metal stress[17]. In wheat, Biochar reduced cadmium toxicity for plants growing in Cd-contaminated saline soil [18].Biochar application decreased the oxidative stress in plants and recovered the antioxidant enzyme activities.

Silicon is the second-most abundant element in the world, and it could promote plant growth and weaken both biological and non-biological stresses $[19,20]$. It has been reported that Si plays a vital role in the transfer and accumulation of $\mathrm{Cd}$ in plants [21]. Si alleviates $\mathrm{Cd}$ toxicity in several ways. It activates the antioxidant system in plants [22], forms $\mathrm{Si}$ and Cd precipitants, and restrains Cd translocation, which weakens its biological activity [23]. In rice, $120 \mathrm{mg} \mathrm{L}^{-1}$ Si decreased Cd accumulation and also reduced the ratio of $\mathrm{Cd}$, transferring from roots to shoots, which lessened the $\mathrm{Cd}$ toxicity [24]. In Pisum sativum $\mathrm{L}$, the application of Si decreased $\mathrm{Cd}$ accumulation and increased the absorption of macronutrients and micronutrients in shoots and roots, which alleviated Cd toxicity [25]. In wheat, the total Cd uptake decreased in the presence of Si [26]. Other examples of silicon application alleviating the poisonous effects of Cd were found in maize [27] and cucumber [28].

Ginger (Zingiber officinale Rosc.), belongs to the Zingiberaceae family. It has been used in tropical and subtropical regions in the world for thousands of years. Ginger is traditionally used in Indian and Chinese systems of medicine for treating the common cold, toothaches, nervous diseases, stomach aches, constipation, and diabetes [29]. Ginger rhizomes are famous for their aromatic odor and spicy taste, traditionally used as spices and herbal ingredients in cooking. Recently, ginger has been used as a raw material for cosmetics, beverages, dried ginger powder, ginger tea, and sliced ginger snacks. There has even been a new bio-functional material developed from ginger [30, 31].

Despite ginger being used around the world, few studies analyzing of heavy metal have been reported on Zingiber officinale. The ones that do exist for the species focus mainly on cultivation, pesticides, food processing, and the medicinal value of the plant. There is no information available in the literature regarding the effect of $\mathrm{Si}$ alleviation on $\mathrm{Cd}$ pollution in ginger. The aim of this study was (1) to observe the physiological indexes of ginger under Cd stress; (2) to explore the effect of varying levels of Si exposure on the growth of ginger under Cd stress; (3) to quantify the effect of Si on Cd content and 
transfer coefficient in the various organs of ginger under Cd stress; and (4) to determine the effect of Si on photosynthesis and antioxidant activity.

\section{Result}

The effect of cadmium stress on the growth and quality of ginger

There is an impact on ginger growth when 1,2 , and $4 \mathrm{mg} / \mathrm{kg}$ of $\mathrm{Cd}$ are applied during the growth process of ginger (Table 1). At 40d, the plant height and fresh weight were significantly lower than the CK at four $\mathrm{mg} / \mathrm{kg}$ Cd level. At $80 \mathrm{~d}$ and $120 \mathrm{~d}$ after the treatment, the physiological indexes of ginger decreased as $\mathrm{Cd}$ levels increased. Above all, the physiological indexes under $2 \mathrm{mg} / \mathrm{kg}$ and $4 \mathrm{mg} / \mathrm{kg}$ of Cd stress were significantly lower than those of the CK. This indicates that the root growth was significantly inhibited, the number of branches was reduced, and the biomass of the above-ground parts was reduced when the Cd level was higher than $2 \mathrm{mg} / \mathrm{kg}$ (Table 1 ).

The quality indexes of ginger rhizomes indicated there were significant differences among the treatments. The yield and dry weight of ginger showed a decreasing trend with the increasing of $\mathrm{Cd}$ levels. The yield decreased by $9.1 \%$, and dry weight decreased by $7.8 \%$ compared with the CK at $2 \mathrm{mg} / \mathrm{kg}$ of $\mathrm{Cd}$. Gingerols act as the primary indicators when evaluating ginger flavor and quality. As seen in Table 2, the content of gingerols significantly decreased as the $\mathrm{Cd}$ level increased. The content of gingerols was reduced by $12.1 \%, 31.0 \%$, and $38.0 \%$ compared with the CK. This showed that the ginger quality was significantly reduced at $2 \mathrm{mg} / \mathrm{kg}$ Cd stress (Table 2 ).

The effect of silicon on the growth and quality of ginger under $\mathrm{Cd}$ stress

Based on the effect of $\mathrm{Cd}$ stress on the growth and quality of ginger, the physiology indexes significantly decreased compared with the CK from the $2 \mathrm{mg} / \mathrm{kg}$ of Cd. Because of this, $2 \mathrm{mg} / \mathrm{kg}$ of Cd was chosen for the background value in the subsequent research. To observe the effect of silicon on the growth and quality of ginger under Cd stress, we used $0 \mathrm{~g} / \mathrm{kg}, 1 \mathrm{~g} / \mathrm{kg}, 2 \mathrm{~g} / \mathrm{kg}$ Si to explore the alleviation effect of varying Si concentrations under $2 \mathrm{mg} / \mathrm{kg}$ of Cd stress. The growth of ginger was promoted after the addition of Si under Cd stress (Fig. 1). There is no significant difference among different treatments at $40 \mathrm{~d}$, but the difference was significant at the rhizome stage. Plant height had increased by $18.8 \%$ and $24.7 \%$ under $\mathrm{Si} 1$ and $\mathrm{Si} 2$ compared with the CK. Meanwhile, the fresh weight of the root and rhizome showed an increasing trend. The fresh weight of the root in Si1 and $\mathrm{Si} 2$ had increased by $10.5 \%$ and $19.3 \%$ compared with the Si0. The fresh weight of rhizome in Si1 and Si2 had increased by $14.3 \%$ and $19.5 \%$ in comparison with the Si 0 . The addition of Si under Cd stress promoted ginger growth, especially in the Si2 treatment (Table 3). Also, the yield of ginger improved dramatically under the Si1 and Si2 treatments, which showed an increase of $14.3 \%$ and $19.5 \%$ compared with the CK. Soluble sugar, crude cellulose, soluble protein, free amino acid, and vitamin $\mathrm{C}$ increased as the application of $\mathrm{Si}$ increased. The effect was the greatest in the Si2 treatment. Application of Si could improve ginger flavor quality. The content of gingerols was improved by $36.8 \%$ and $63.2 \%$ under Si1 and Si2, compared with the SiO (Table 4). 
The effect of silicon on Cd content, $\mathrm{Cd}$ accumulation in different organ of ginger under $\mathrm{Cd}$ stress

Cd content was significantly reduced after the addition of Si under $2 \mathrm{mg} / \mathrm{kg} \mathrm{Cd}$ stress (Table 5). At 40d and $80 \mathrm{~d}$, the $\mathrm{Cd}$ content of the rhizome and the root was significantly reduced after the addition of $\mathrm{Si}$. At the same time, the $\mathrm{Cd}$ content of the stem and the leaves had reduced, but not significantly so. At $120 \mathrm{~d}$, $\mathrm{Cd}$ content of each part was dramatically decreased after applying $\mathrm{Si}$. The $\mathrm{Cd}$ content had reduced from $0.2566,0.1070$, and $0.0580 \mu \mathrm{g} / \mathrm{g}$, respectively, to $0.1861,0.0686$, and $0.0277 \mu \mathrm{g} / \mathrm{g}$, respectively, in motherginger, son-ginger, and grandson-ginger under the Si2 treatment (Table 5).

As Table 6 shows, Cd accumulation in the root and rhizome was less than the CK under the Si1 treatment. The $\mathrm{Cd}$ accumulation in the aboveground part changed insignificantly and showed a slightly increasing trend, indicating that $\mathrm{Cd}$ accumulation in the aboveground part was promoted after applying $\mathrm{Si}$. The $\mathrm{Cd}$ accumulation under the $\mathrm{Si} 2$ treatment significantly decreased compared with the $\mathrm{CK}$, indicating that highconcentration Si treatment significantly inhibited $\mathrm{Cd}$ accumulation. In conclusion, $\mathrm{Si}$ in ginger could promote or inhibit $\mathrm{Cd}$ accumulation, depending on the concentration of $\mathrm{Si}$ in the soil (Table 6).

The effect of silicon on cadmium absorption coefficient and transfer coefficient under $\mathrm{Cd}$ stress

The primary transfer coefficient under the Si2 treatment was significantly lower than the $\mathrm{SiO}$ and $\mathrm{Si} 1$ treatments, implying that higher concentrations of Si inhibited Cd migration from the root to the rhizome (Table 7). The secondary transfer coefficient under the Si1 treatment was significantly higher than in the $\mathrm{SiO}$ and $\mathrm{Si} 2$ treatments, which indicates that the lower concentration of silicon promotes the transfer of $\mathrm{Cd}$ from the rhizome to the ground. The root absorption coefficient of the Si2 treatment was significantly lower than in the SiO and Si1 treatments, which indicates that a high concentration of silicon could dramatically inhibit the root from absorbing $\mathrm{Cd}$ from the soil. The aboveground absorption coefficient of the Si2 treatment (0.023) was significantly lower than the SiO (0.040) and Si1 (0.038) treatments, indicating that a high concentration of silicon inhibited the plant from absorbing $\mathrm{Cd}$ from the soil (Table 7).

The effect of silicon on the photosynthesis of ginger leaves under Cd stress

The effect of $\mathrm{Si}$ on the diurnal photosynthetic changes of ginger at the rhizome expansion stage (120 d) under $2 \mathrm{mg} / \mathrm{kg} \mathrm{Cd}$ stress was analyzed (Fig. 2). The Pn of ginger leaves appeared as double peaks in one day, and the diurnal variation trend of each treatment was similar, ranked as Si2 > Si1 > Si0. The Pn was the least at 13:00, and the Pn of the Si1 and Si2 treatments had improved by $14.4 \%$ and $24.6 \%$ compared with the $\mathrm{CK}$. Therefore, the addition of $\mathrm{Si}$ under $\mathrm{Cd}$ stress lessened the damage to the ginger plant under $\mathrm{Cd}$ stress by weakening the decreasing trend of the Pn. At this time, the $\mathrm{Si} 1$ and $\mathrm{Si} 2$ treatments increased by $4.8 \%$ and $10.2 \%$ compared with the Si0 treatment. The $\mathrm{Ci}$ was opposite to the trend of the $\mathrm{Gs}$, and the lowest reading for $\mathrm{Ci}$ was at 13:00, and $\mathrm{Si} 0>\mathrm{Si} 1>\mathrm{Si} 2$ was adopted in all treatments. The trend of $\mathrm{Ci}$ was the opposite of that of Gs. Ci was the lowest at 13:00, ranked as Si0 > Si1 > Si2 (Fig. 2). 
Under $2 \mathrm{mg} / \mathrm{kg}$ of Cd stress, the chlorophyll fluorescence parameters of functional leaves in ginger under different Si treatments showed a similar diurnal variation trend. As treatment time increased, the Fv/Fm of ginger leaves showed a trend of declining and then rising, reaching the lowest value at 13:00. The increasing range of the Si1 and the Si2 treatments reached the maximum compared with the SiO treatment at this time, and then the Fv/Fm gradually recovered. The daily variation trend of $\Phi \mathrm{PS} \otimes$ and qP under varying $\mathrm{Si}$ treatments is similar to $\mathrm{Fv} / \mathrm{Fm}$. The $\mathrm{Fv} / \mathrm{Fm}$ reflects the internal energy conversion efficiency of the PSII reaction center. The ФPS reflected the actual PSII light energy capture efficiency when part of the PSII reaction center closed. They both decreased under the strong light and recovered under the weak light, indicating that the addition of Si improved the tolerance to light. During diurnal variation, the variation trend of NPQ was similar, ranked as SiO > Si1 > Si2. At 13:00, NPQ reached the peak. At this time, Si1 decreased by $8.5 \%$ compared with the Si0 treatment, and the Si2 treatment decreased by $12.3 \%$ compared with the Si0 treatment. Subsequently, NPQ declined. At 17:00, the Si1 treatment decreased by $5.5 \%$, and the Si2 treatment decreased by $8.8 \%$ (Fig. 3).

The effect of silicon on antioxidant enzyme activities in ginger leaves under Cd stress

The ROS level exhibited a rising trend as the treatment days increased (Fig. 4). At $80 \mathrm{~d}$, the increasing trend of $\mathrm{O}^{2-}$. was significant. The $\mathrm{H}_{2} \mathrm{O}_{2}$ increased dramatically at $120 \mathrm{~d}$. In the same treatment, the $\mathrm{H}_{2} \mathrm{O}_{2}$ content of ginger leaves had decreased as the Si concentration increased, ranked as Si2 > Si1 > SiO. At $120 \mathrm{~d}$, the $\mathrm{O}^{2-}$. had been reduced by $18.9 \%$ and $27.8 \%$ under the Si0 treatment Si1 treatments, respectively, compared with the SiO treatment (Fig. 4).

The SOD, POD, and CAT increased as the Si content increased under two $\mathrm{mg} / \mathrm{kg} \mathrm{Cd}$ (Fig. 5). There was a significant difference in the three treatments, and the Si2 treatment was the highest. With the extension of time, the SOD activity of the SiO treatment gradually decreased. The SOD activity of the Si1 treatment and the Si2 treatment increased and then decreased. At 120d, the SOD activity of the Si2 treatment was the highest, the Si1treatment was second, and the SiO treatment was the lowest, suggesting that the addition of Si inhibited the SOD activity declining (Fig. 5). The most minor damage to the membrane system in the ginger leaf was in the Si2 treatment, while the Si1 treatment was second. The Si0 treatment showed the most critical damage to the membrane system. During the whole growth stage, the extent of damage was increasingly severe as time went on. At 120d, the MDA content reached the maximum. The MDA of the Si 1 treatment and the $\mathrm{Si} 2$ treatment was reduced by $14.6 \%$ and $20.0 \%$ compared with the Si0 treatment which indicates that the damage of the membrane system in the ginger leaf was lower when siliconcontaining fertilizer was applied. The Proline content significantly decreased from the SiO treatment to the Si1 treatment, to the Si2 treatment during the whole growth period (Fig. 6).

\section{Discussion}

Silicon augmented plant growth and biomass 
Heavy metal stress can destroy the physiological and biochemical processes in plants [32]. Our studies indicated that ginger growth was inhibited under Cd stress. Similarly, results showing negative effects of Cd on rice [33], wheat[34], cotton [35], maize[36] , and peanut[37] have been reported. Our studies indicated that the restriction of ginger growth was alleviated by the application of Si under Cd stress conditions, as reflected by the growth index (plant height, stem diameter, and fresh and dry weight) and plant quality (soluble sugar, soluble protein, crude cellulose, vitamin $\mathrm{C}$, and gingerol), as well as the absorption and transfer of $\mathrm{Cd}$ in the plant, and the photosynthesis and antioxidant enzyme activity. As our results revealed, the plant height of ginger increased by $18.8 \%$ and $24.7 \%$ under the Si1 treatment and the Si2 treatment compared with the CK. The fresh weight of the rhizome in the Si1 treatment and the Si2 treatment increased by $14.3 \%$ and $19.5 \%$, respectively, in comparison with the Si0 treatment (Table 3), proving the beneficial effects of $\mathrm{Si}$ on the growth of ginger. These results were in agreement with previous research in which $\mathrm{Si}$ improved the biomass of rice under Cd stress. Exogenous Si enhances rice metabolism when absorbed by the plants [38]. For example, when $120 \mathrm{mg} \mathrm{L}^{-1} \mathrm{Si}$ was added to a solution applied to the plants, it had powerful effects on the growth of rice seedlings, particularly those being planted at the highest Cd levels. Similar results were found in cotton. Plant height, root length, leaf area, and the number of leaves of cotton decreased under cadmium (Cd) stress. When Si was applied, the toxic effect generated by cadmium was eliminated, and the growth of cotton was promoted, reflected as an increase in plant height, root length, leaf area, and the number of leaves [39].

\section{Silicon reduced $\mathrm{Cd}$ accumulation}

The primary transfer coefficient under the Si2 treatment (0.519) was significantly lower than the Si0 treatment (0.590) and the Si1treatment (0.573), as shown in Table 7. There was less Cd transferred from root to rhizome in ginger under the Si2 treatment. There are three possible explanations for the inhibition of $\mathrm{Cd}$ transfer from root to rhizome in plants by adding $\mathrm{Si}$. (1) Si precipitates lignin in cell walls and promotes $\mathrm{Cd}^{2+}$ bound to cell walls, then inhibits heavy metals transferring from roots to shoots [40]. It was reported that the mechanism was suitable for rice seedlings and maize[33, 36]. (2) Si could form the complex or co-precipitation with the toxic heavy metal ions. For example, in barley, Si formed the complex with B in the soil. Thus, the content of B was decreased [41]. (3) Si reduced Cd content in cell organelle fractions of leaves, such as in peanuts [37]. However, in our study, the mechanism was unknown, and all of the three hypotheses listed here are possible, but further verification is needed.

Silicon restored photosynthetic efficiency

$\mathrm{Cd}$ could reduce chlorophyll synthesis, the photochemical quantum yield of $\Phi P S I I$, and the $\mathrm{CO}_{2}$ fixation rate. It was reported that in maize, chlorophyll synthesis and the photochemical quantum yield of $\Phi P S I I$ decreased under $\mathrm{Cd}$ stress [42]. In durum wheat, Cd affected chlorophyll fluorescence [43]. However, the exogenous addition of $\mathrm{Si}$ under $\mathrm{Cd}$ stress had powerful effects on chlorophyll synthesis and photosynthetic machinery. In our study, the Pn was the least at 13:00, and the Pn of the Si1 and the Si2 treatments were improved by $14.4 \%$ and $24.6 \%$, respectively, compared with the CK. Therefore, Si addition under $\mathrm{Cd}$ stress alleviated the damage to the ginger plants by weakening the decreasing trend of the $\mathrm{Pn}$ 
under $\mathrm{Cd}$ stress (Figure 2). The results were similar in peas, cotton, and maize. In the pea plant, Si addition promoted the contents of chlorophyll pigment and carotene [44]. The same condition occurred in cotton seedlings; the contents of photosynthetic pigments were increased with the addition of exogenous $\mathrm{Si}$ [45]. The positive effects of Si on photosynthesis could be due to the destroyed uptake of heavy metals, which could enhance PSI and PSII activation [46]. In maize, Si alleviates Cd toxicity by increasing photosynthetic rate in the modified bundle sheath cells [47].

Silicon modulated antioxidant activity

Plants could use a series of strategies against the toxic effects of heavy metals under heavy metal stress conditions. The activities of SOD, POD, and CAT are of considerable significance to scavenge the ROS caused by heavy metals $[48,49]$. Previous studies have reported that Si mediates up-regulation of the antioxidant defense system by increasing the SOD, POD, CAT, and GR activity [50, 51].Alleviation of heavy metals toxicity by Si was correlated with protection against oxidative damage. In a previous report, $\mathrm{Si}$ could alleviate $\mathrm{Cd}$ stress because of a noticeable increase in antioxidant activity and a decrease in MDA in pakochi [52]. In cotton, Si addition could significantly improve the plant's defense capacity against oxidative damage caused by $\mathrm{Cd}$ stress. MDA, $\mathrm{H}_{2} \mathrm{O}_{2}$, and electrolyte leakage were reduced, and SOD, POD, APX, and CAT activities were enhanced under Cd stress [45]. In cucumber, the application of Si could eliminate heavy metal Mn toxicity by improving antioxidant activity, according to Shi et al.[53].

Our study showed that SOD, POD, and CAT activities were increased as the Si content increased under Cd stress (Fig.5). At 120d, MDA of the Si1 treatment and the Si2 treatment was reduced by $14.6 \%$ and $20.0 \%$ compared with the SiO treatment, indicating that the damage of the membrane system in the ginger leaf was lower when silicon-containing fertilizer was applied. Proline content was markedly decreased from the Si0 treatment to the Si1 treatment to the Si2 treatment during the whole growth period (Fig.6).

\section{Conclusion}

Cd stress inhibited the growth and quality of ginger. Soil conditioner Si alleviated the harmful effects of Cd stress on ginger plants: The Si2 treatment $(2 \mathrm{~g} / \mathrm{kg})$ was the most effective. The fresh weight of rhizomes in the Si1 treatment and the Si2 treatment were increased by $14.3 \%$ and $19.5 \%$, respectively, in comparison with the Si0 treatment. The yield of ginger was improved dramatically under the Si1 and the Si2 treatments, increased by $14.3 \%$ and $19.5 \%$ compared with the CK. The content of soluble sugar, soluble protein, crude cellulose, free amino acid, and vitamin C grew with the application of Si increasing. The use of Si could improve ginger flavor quality. Gingerol was improved by $36.8 \%$ and $63.2 \%$ under the Si1 and Si2 treatments, respectively, compared with the Si0 treatment. At $120 \mathrm{~d}$, after applying Si, the Cd content in various organs of the ginger plant was reduced. The Pn of ginger leaves appeared in double peaks in one day, and the diurnal variation trend of each treatment was similar, ranked as Si2 > Si1 $>$ Si0. Overall, our results suggest that $\mathrm{Si}$ could alleviate the negative effect of $\mathrm{Cd}$ stress on ginger, and the Si2 treatment was the most effective. 


\section{Methods}

\section{Experimental materials}

The experiment took place at Shandong Agricultural University at the experimental horticulture station. The ginger variety used was "Laiwudajiang" (WanXing Food company, LaiWu, Shandong Province). The soil tested was $\mathrm{pH}=7.3$, with $100.5 \mathrm{mg} / \mathrm{kg}$ alkali-hydrolyzed nitrogen $(\mathrm{N}), 63.4 \mathrm{mg} / \mathrm{kg}$ available phosphorus $\left(\mathrm{P}_{2} \mathrm{O}_{5}\right)$, and $127.8 \mathrm{mg} / \mathrm{kg}$ available potassium $\left(\mathrm{K}_{2} \mathrm{O}\right)$. The background value of soil $\mathrm{Cd}$ was $0.14 \mathrm{mg} / \mathrm{kg}$. The soil used for the study was air-dried and put into a plastic basin with a $30 \mathrm{~cm}$ diameter and a height of $28 \mathrm{~cm}$. Each basin contained $8.0 \mathrm{~kg}$ of air-dried soil. The ginger was planted when it germinated to $1 \mathrm{~cm}$. Two plants were grown per pot.

\section{Experimental design}

The experiment followed the environmental quality standard GB15618-2009. The Cd level was set at zero, one, two, and four $\mathrm{mg} / \mathrm{kg}$ (soil). There were 10 basins per treatment, and each treatment had three replicates. Varying concentrations of cadmium chloride $(\mathrm{CdCl} 2 \cdot 2.5 \mathrm{H} 20)$ solution was added to the soil via sewage irrigation once the ginger emerged. The $\mathrm{CdCl} 2 \cdot 2.5 \mathrm{H} 20$ was applied in this way to ensure the uniform distribution of heavy metals in the soil and to prevent loss from the plastic containers. Other aspects of the experiment were conducted according to the standard method. Samples were collected at the seedling stage, trilling stage, and rhizome expansion stage, respectively (i.e., 40 d, 80 d, and 120 d), after the sewage irrigation treatment, and relevant indexes were determined.

Based on the experiment done in the first year, the stress level of Cd was set at two $\mathrm{mg} / \mathrm{kg}$ (soil), and the amount of silicon fertilizer was zero, one, and two $\mathrm{g} / \mathrm{kg}$ (soil), respectively. There were 10 pots in each treatment, and each treatment had three replicates. When sowing ginger, the silicon fertilizer mixed with the $10 \mathrm{~cm}$ topsoil in a basin. Two $\mathrm{mg} / \mathrm{kg} \mathrm{Cd}$ (in terms of $\mathrm{Cd}^{2+}$ ) were applied to the soil using the sewage irrigation method when the ginger emerged. The sewage irrigation method was used to ensure that the heavy metals were evenly distributed in the soil and not lost from the pot. Samples were taken at $40 \mathrm{~d}, 80$ $\mathrm{d}$, and $120 \mathrm{~d}$ after treatment, and relevant indexes were measured.

\section{Determination methods}

\section{Determination of growth indexes}

The plants were taken and rinsed with water. Plant height, stem diameter, branch number, leaf number, root, stem, leaf and fresh weight of rhizome were measured.

After 20 minutes in the drying oven at $105^{\circ} \mathrm{C}$, the samples were dried to constant weight at $75{ }^{\circ} \mathrm{C}$. The dry matter of each organ was measured.

Determination of quality 
The volume of soluble proteins, soluble sugars, free amino acids, crude fiber, and vitamin C were measured using various methods. Soluble proteins were measured by staining with Coomassie Brilliant Blue. Soluble sugar content was determined using the anthrone colorimetry technique [54]. Free amino acids were measured using the ninhydrin method [55]. Crude fiber volume was determined by the acidwash method. And vitamin C was measured using the standard of 2,6-dichloro indophenol [56].

To measure the content of gingerols, $1 \mathrm{~g}$ of ginger powder was added to the $100-\mathrm{ml}$ volumetric flask, then $70 \mathrm{ml}$ acetone was mixed into the mixture and shaken for $1 \mathrm{~h}$ at $50^{\circ} \mathrm{C}$. The mixture was then cooled and diluted with acetone to volume. Filter liquor was used for determining the content of gingerols [57].

Determination of $\mathrm{Cd}$

$1.0 \mathrm{~g}$ dry sample of mother-ginger, son-ginger, and grandson-ginger were placed in a conical flask, respectively. The dry samples of ginger were digested using the operation method of Srivastava RK [58], and the content of $\mathrm{Cd}$ in the plant was measured using a Japanese atomic absorption spectrophotometer.

Antioxidant enzyme activities Malondialdehyde (MDA) and superoxide dismutase (SOD), peroxidase (POD) and catalase (CAT) enzyme extraction and evaluation were performed according to the procedure shown in Yin et al [59]. Three biological replicates were carried out for each sample. The parameters were determined in a Hitachi U-2000 UV/Vis spectrophotometer.

$\mathrm{O}_{2} \cdot$ generation rate and $\mathrm{H}_{2} \mathrm{O}_{2}$ content

The superoxide $\left(\mathrm{O}_{2}^{-}\right)$generation rate was determined by using the hydroxylamine oxidation method [60]. The $\mathrm{H}_{2} \mathrm{O}_{2}$ content was measured following the procedure used by Gay and Gebicki [61].

Photosynthetic parameters

The third functioning leaf was selected to analyze the Pn (net photosynthetic rate), the Gs (stomatal conductance), the $\mathrm{Ci}$ (intercellular $\mathrm{CO}_{2}$ concentration), and the $\mathrm{E}$ (transpiration rate) using a CIRAS-1 portable photosynthesis system (PP Systems, Hitchin, UK) as described by Liu et al. [62].

Chlorophyll fluorescence parameters

The Fm (maximal fluorescence), the Fo (minimal fluorescence), the Fs (steady-state value of fluorescence), the Fo' (minimal fluorescence in the light), and the Fm' (maximum fluorescence in the lightadapted state) were measured using a FMS-2 portable fluorescence meter (Hansatech, Kings Lynn, UK). The values of Fv/Fm (The photochemical efficiency of PSII), ФPSII (Quantum efficiency of PSII), qP (Photochemical quenching coefficient), and NPQ (Nonphotochemical quenching) were calculated as described by Cao et al. [63].

Primary transfer coefficient and absorption coefficient 
The primary and secondary transfer coefficients were calculated as follows:

Primary transfer coefficient $=\mathrm{Cd}$ content of rhizome/ Cd content of root

Secondary transfer coefficient $=\mathrm{Cd}$ content of aboveground part/ Cd content of rhizome .

The various absorption coefficients were calculated using the following formulae:

Root absorption coefficient $=$ Cd content of root/ Cd content of the soil

Aboveground absorption coefficient $=\mathrm{Cd}$ content of aboveground $/ \mathrm{Cd}$ content of the soil.

Statistical analyses

DPS7.05 software was used to test the difference of the data (Duncan's new complex range method), and Microsoft Excel 2010 software was used to manage and analyze the test data.

\section{Declarations}

\section{Ethics approval and consent to participate}

Not applicable

\section{Consent for publication}

Not applicable.

\section{Availability of data and material}

Not applicable

\section{Competing interests}

The authors declare that they have no competing interests.

\section{Funding}

This study was supported by the National Characteristic Vegetable Industry Technology System Project (Grant No. CARS-24-A-09) and the Shandong Province's dual-class discipline construction project (Grant No. SYL2017YSTD06).The funding organizations provided the financial support to the research projects, but were not involved in the design of the study, data collection, analysis of the data, or the writing of the manuscript.

\section{Authors' Contributions:}

As designed and performed the experiment, ZC and JZ did the experiment. BC analyzed the data. $\mathrm{KX}$ provided the guidance during all experiments. All authors have read and approved the manuscript.

\section{Acknowledgments:}


We thank Margaret J. Sporck-Koehler, PhD, from Liwen Bianji, Edanz Editing China (www.liwenbianji.cn/ac), for editing the English text of a draft of this manuscript.

\section{Abbreviations}

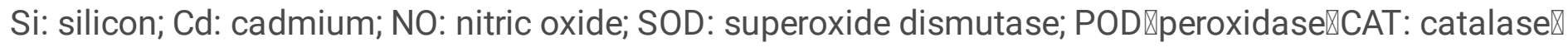
MDA: malondialdehyde; $\mathrm{Pn}$ : net photosynthetic rate区Gs: stomatal conductance $\mathbb{C i}$ intercellular $\mathrm{CO}_{2}$ concentration $\mathbb{\mathrm { E }}$ : transpiration rate $\mathbb{\mathrm { F } m}$ : maximal fluorescence Fo: minimal fluorescence; Fs: steady-state value of fluorescence; Fo':minimal fluorescence in the light囚Fm': maximum fluorescence in the lightadapted state; Fv/Fm: the photochemical efficiency of PSII; ФPSIl: quantum efficiency of PSIl; qP: photochemical quenching coefficient; NPQ: nonphotochemical quenching.

\section{References}

1. Zhou Q, Yang Y, Yang Z: Molecular dissection of cadmium-responsive transcriptome profile in a lowcadmium-accumulating cultivar of Brassica parachinensis. Ecotoxicol Environ Saf 2019, 176:85-94.

2. Gill SS, Tuteja N: Cadmium stress tolerance in crop plants: probing the role of sulfur. Plant Signal Behav 2011, 6(2):215-222.

3. Lysenko EA, Klaus AA, Kartashov AV, Kusnetsov VV: Specificity of Cd, Cu, and Fe effects on barley growth, metal contents in leaves and chloroplasts, and activities of photosystem I and photosystem II. Plant Physiol Biochem 2019, 147:191-204.

4. Flores-Caceres ML, Hattab S, Hattab S, Boussetta H, Banni M, Hernandez LE: Specific mechanisms of tolerance to copper and cadmium are compromised by a limited concentration of glutathione in alfalfa plants. PLANT SCI 2015, 233:165-173.

5. Zhao FJ, Ma Y, Zhu YG, Tang Z, McGrath SP: Soil contamination in China: current status and mitigation strategies. ENVIRON SCI TECHNOL 2015, 49(2):750-759.

6. Rafati RM, Rafati RM, Kazemi S, Moghadamnia AA: Cadmium toxicity and treatment: An update. Caspian J Intern Med 2017, 8(3):135-145.

7. Souza VL, de Almeida AA, Lima SG, de M CJ, Da CSD, Mangabeira PA, Gomes FP: Morphophysiological responses and programmed cell death induced by cadmium in Genipa americana L. (Rubiaceae). BIOMETALS 2011, 24(1):59-71.

8. Dixit V, Pandey V, Shyam R: Differential antioxidative responses to cadmium in roots and leaves of pea (Pisum sativum L. cv. Azad). J EXP BOT 2001, 52(358):1101-1109.

9. Li R, Luo X, Zhu Y, Zhao L, Li L, Peng Q, Ma M, Gao Y: ATM signals to AMPK to promote autophagy and positively regulate DNA damage in response to cadmium-induced ROS in mouse spermatocytes. ENVIRON POLLUT 2017, 231(Pt 2):1560-1568.

10. Pormehr M, Ghanati F, Sharifi M, McCabe PF, Hosseinkhani S, Zare-Maivan H: The role of SIPK signaling pathway in antioxidant activity and programmed cell death of tobacco cells after exposure to cadmium. PLANT SCI 2019, 280:416-423. 
11. Besson-Bard A, Gravot A, Richaud P, Auroy P, Duc C, Gaymard F, Taconnat L, Renou JP, Pugin A, Wendehenne D: Nitric oxide contributes to cadmium toxicity in Arabidopsis by promoting cadmium accumulation in roots and by up-regulating genes related to iron uptake. PLANT PHYSIOL 2009, 149(3):1302-1315.

12. Saxena I, Shekhawat GS: Nitric oxide (NO) in alleviation of heavy metal induced phytotoxicity and its role in protein nitration. Nitric Oxide 2013, 32:13-20.

13. Kaya C, Okant M, Ugurlar F, Alyemeni MN, Ashraf M, Ahmad P: Melatonin-mediated nitric oxide improves tolerance to cadmium toxicity by reducing oxidative stress in wheat plants. CHEMOSPHERE 2019, 225:627-638.

14. Singh A, Sharma L, Mallick N: Antioxidative role of nitric oxide on copper toxicity to a chlorophycean alga, Chlorella. Ecotoxicol Environ Saf 2004, 59(2):223-227.

15. Zhang W, Chen W: Role of salicylic acid in alleviating photochemical damage and autophagic cell death induction of cadmium stress in Arabidopsis thaliana. Photochem Photobiol Sci 2011, 10(6):947-955.

16. Zhang W, Song J, Yue S, Duan K, Yang H: MhMAPK4 from Malus hupehensis Rehd. decreases cell death in tobacco roots by controlling Cd(2+) uptake. Ecotoxicol Environ Saf 2019, 168:230-240.

17. Rizwan M, Ali S, Qayyum MF, Ibrahim M, Zia-ur-Rehman M, Abbas T, Ok YS: Mechanisms of biocharmediated alleviation of toxicity of trace elements in plants: a critical review. Environ Sci Pollut Res Int 2016, 23(3):2230-2248.

18. Abbas T, Rizwan M, Ali S, Adrees M, Zia-Ur-Rehman M, Qayyum MF, Ok YS, Murtaza G: Effect of biochar on alleviation of cadmium toxicity in wheat (Triticum aestivum L.) grown on Cdcontaminated saline soil. Environ Sci Pollut Res Int 2018, 25(26):25668-25680.

19. Rizwan M, Ali S, Ibrahim M, Farid M, Adrees M, Bharwana SA, Zia-Ur-Rehman M, Qayyum MF, Abbas F: Mechanisms of silicon-mediated alleviation of drought and salt stress in plants: a review. Environ Sci Pollut Res Int 2015, 22(20):15416-15431.

20. Cui J, Liu T, Li F, Yi J, Liu C, Yu H: Silica nanoparticles alleviate cadmium toxicity in rice cells: Mechanisms and size effects. ENVIRON POLLUT 2017, 228:363-369.

21. Shi Z, Yang S, Han D, Zhou Z, Li X, Liu Y, Zhang B: Silicon alleviates cadmium toxicity in wheat seedlings (Triticum aestivum $L$.) by reducing cadmium ion uptake and enhancing antioxidative capacity. Environ Sci Pollut Res Int 2018, 25(8):7638-7646.

22. Mohaghegh $\mathrm{P}$, Khoshgoftarmanesh AH, Shirvani M, Sharifnabi B, Nili N: Effect of Silicon Nutrition on Oxidative Stress Induced by Phytophthora melonis Infection in Cucumber. PLANT DIS 2011, 95(4):455-460.

23. Liu J, Ma J, He C, Li X, Zhang W, Xu F, Lin Y, Wang L: Inhibition of cadmium ion uptake in rice (Oryza sativa) cells by a wall-bound form of silicon. NEW PHYTOL 2013, 200(3):691-699.

24. Srivastava RK, Pandey P, Rajpoot R, Rani A, Gautam A, Dubey RS: Exogenous application of calcium and silica alleviates cadmium toxicity by suppressing oxidative damage in rice seedlings. PROTOPLASMA 2015, 252(4):959-975. 
25. Jan S, Alyemeni MN, Wijaya L, Alam P, Siddique KH, Ahmad P: Interactive effect of 24-epibrassinolide and silicon alleviates cadmium stress via the modulation of antioxidant defense and glyoxalase systems and macronutrient content in Pisum sativum L. seedlings. BMC PLANT BIOL 2018, 18(1):146.

26. Rizwan M, Meunier JD, Davidian JC, Pokrovsky OS, Bovet N, Keller C: Silicon alleviates Cd stress of wheat seedlings (Triticum turgidum L. cv. Claudio) grown in hydroponics. Environ Sci Pollut Res Int 2016, 23(2):1414-1427.

27. Vaculík M, Lux A, Luxová $M$, Tanimoto E, Lichtscheidl I: Silicon mitigates cadmium inhibitory effects in young maize plants. ENVIRON EXP BOT 2009, 67(1):52-58.

28. Feng J, Shi Q, Wang X, Wei M, Yang F, Xu H: Silicon supplementation ameliorated the inhibition of photosynthesis and nitrate metabolism by cadmium (Cd) toxicity in Cucumis sativus L. SCI HORTICAMSTERDAM 2010, 123(4):521-530.

29. Dedov VN, Tran VH, Duke CC, Connor M, Christie MJ, Mandadi S, Roufogalis BD: Gingerols: a novel class of vanilloid receptor (VR1) agonists. Br J Pharmaco/ 2002, 137(6):793-798.

30. Chan EWC, Lim YY, Wong LF, Lianto FS, Wong SK, Lim KK, Joe CE, Lim TY: Antioxidant and tyrosinase inhibition properties of leaves and rhizomes of ginger species. FOOD CHEM 2008, 109(3):477-483.

31. Chrubasik S, Pittler MH, Roufogalis BD: Zingiberis rhizoma: A comprehensive review on the ginger effect and efficacy profiles. PHYTOMEDICINE 2005, 12(9):684-701.

32. KE S: Effects of Copper on the Photosynthesis and Oxidative Metabolism of Amaranthus tricolor Seedlings. Agricultural Sciences in China 2007, 6(10):1182-1192.

33. Tripathi DK, Singh VP, Kumar D, Chauhan DK: Impact of exogenous silicon addition on chromium uptake, growth, mineral elements, oxidative stress, antioxidant capacity, and leaf and root structures in rice seedlings exposed to hexavalent chromium. ACTA PHYSIOL PLANT 2012, 34(1):279-289.

34. Rizwan $\mathrm{M}$, Meunier JD, Miche $\mathrm{H}$, Keller $\mathrm{C}$ : Effect of silicon on reducing cadmium toxicity in durum wheat (Triticum turgidum L. cv. Claudio W.) grown in a soil with aged contamination. J HAZARD MATER 2012, 209-210:326-334.

35. Farooq MA, Ali S, Hameed A, Ishaque W, Mahmood K, Iqbal Z: Alleviation of cadmium toxicity by silicon is related to elevated photosynthesis, antioxidant enzymes; suppressed cadmium uptake and oxidative stress in cotton. Ecotoxicol Environ Saf 2013, 96:242-249.

36. Vaculik M, Pavlovic A, Lux A: Silicon alleviates cadmium toxicity by enhanced photosynthetic rate and modified bundle sheath's cell chloroplasts ultrastructure in maize. Ecotoxicol Environ Saf 2015, 120:66-73.

37. Shi G, Cai Q, Liu C, Wu L: Silicon alleviates cadmium toxicity in peanut plants in relation to cadmium distribution and stimulation of antioxidative enzymes. PLANT GROWTH REGUL 2010, 61(1):45-52.

38. Guo L, Chen A, He N, Yang D, Liu M: Exogenous silicon alleviates cadmium toxicity in rice seedlings in relation to Cd distribution and ultrastructure changes. J SOIL SEDIMENT 2018, 18(4):1691-1700. 
39. Farooq MA, Ali S, Hameed A, Ishaque W, Mahmood K, Iqbal Z: Alleviation of cadmium toxicity by silicon is related to elevated photosynthesis, antioxidant enzymes; suppressed cadmium uptake and oxidative stress in cotton. Ecotoxicol Environ Saf 2013, 96:242-249.

40. Ma JF, Yamaji N: Silicon uptake and accumulation in higher plants. TRENDS PLANT SCI 2006, 11(8):392-397.

41. Gunes A, Inal A, Bagci EG, Coban S, Pilbeam DJ: Silicon mediates changes to some physiological and enzymatic parameters symptomatic for oxidative stress in spinach (Spinacia oleracea L.) grown under B toxicity. SCI HORTIC-AMSTERDAM 2007, 113(2):113-119.

42. Da Silva AJ, Do Nascimento CWA, Da Silva Gouveia-Neto A, Da Silva-Jr EA: LED-Induced Chlorophyll Fluorescence Spectral Analysis for the Early Detection and Monitoring of Cadmium Toxicity in Maize Plants. Water, Air, \& Soil Pollution 2012, 223(6):3527-3533.

43. Paunov M, Koleva L, Vassilev A, Vangronsveld J, Goltsev V: Effects of Different Metals on Photosynthesis: Cadmium and Zinc Affect Chlorophyll Fluorescence in Durum Wheat. INT J MOL SCI 2018, 19(3).

44. Jan S, Alyemeni MN, Wijaya L, Alam P, Siddique KH, Ahmad P: Interactive effect of 24-epibrassinolide and silicon alleviates cadmium stress via the modulation of antioxidant defense and glyoxalase systems and macronutrient content in Pisum sativum L. seedlings. BMC PLANT BIOL 2018, 18(1):146.

45. Farooq MA, Ali S, Hameed A, Ishaque W, Mahmood K, Iqbal Z: Alleviation of cadmium toxicity by silicon is related to elevated photosynthesis, antioxidant enzymes; suppressed cadmium uptake and oxidative stress in cotton. Ecotoxicol Environ Saf 2013, 96:242-249.

46. Adrees M, Ali S, Rizwan M, Zia-Ur-Rehman M, Ibrahim M, Abbas F, Farid M, Qayyum MF, Irshad MK: Mechanisms of silicon-mediated alleviation of heavy metal toxicity in plants: A review. Ecotoxicol Environ Saf 2015, 119:186-197.

47. Vaculik M, Pavlovic A, Lux A: Silicon alleviates cadmium toxicity by enhanced photosynthetic rate and modified bundle sheath's cell chloroplasts ultrastructure in maize. Ecotoxicol Environ Saf 2015, 120:66-73.

48. Anjum SA, Tanveer M, Hussain S, Bao M, Wang L, Khan I, Ullah E, Tung SA, Samad RA, Shahzad B: Cadmium toxicity in Maize (Zea mays L.): consequences on antioxidative systems, reactive oxygen species and cadmium accumulation. Environ Sci Pollut Res Int 2015, 22(21):17022-17030.

49. Li D, Chen G, Lu Q, Li Y, Wang J, Li H: Responses of two kidney bean (Phaseolus vulgaris) cultivars to the combined stress of sulfur deficiency and cadmium toxicity. BIOMETALS 2018, 31(1):17-28.

50. Shekari F, Abbasi A, Mustafavi SH: Effect of silicon and selenium on enzymatic changes and productivity of dill in saline condition. Journal of the Saudi Society of Agricultural Sciences 2017, 16(4):367-374.

51. Liang Y, Chen Q, Liu Q, Zhang W, Ding R: Exogenous silicon (Si) increases antioxidant enzyme activity and reduces lipid peroxidation in roots of salt-stressed barley (Hordeum vulgare L.). J PLANT PHYSIOL 2003, 160(10):1157-1164. 
52. Song A, Li Z, Zhang J, Xue G, Fan F, Liang Y: Silicon-enhanced resistance to cadmium toxicity in Brassica chinensis $L$. is attributed to Si-suppressed cadmium uptake and transport and Si-enhanced antioxidant defense capacity. J HAZARD MATER 2009, 172(1):74-83.

53. Shi Q, Bao Z, Zhu Z, He Y, Qian Q, Yu J: Silicon-mediated alleviation of Mn toxicity in Cucumis sativus in relation to activities of superoxide dismutase and ascorbate peroxidase. PHYTOCHEMISTRY 2005, 66(13):1551-1559.

54. Jiang $Y$, Huang B: Protein Alterations in Tall Fescue in Response to Drought Stress and Abscisic Acid. CROP SCI 2002, 42(1):202-207.

55. Wu Y, Hussain M, Fassihi R: Development of a simple analytical methodology for determination of glucosamine release from modified release matrix tablets. J Pharm Biomed Anal 2005, 38(2):263269.

56. Karpinski S, Escobar C, Karpinska B, Creissen G, Mullineaux PM: Photosynthetic electron transport regulates the expression of cytosolic ascorbate peroxidase genes in Arabidopsis during excess light stress. PLANT CELL 1997, 9(4):627-640.

57. Chen Z, Xu J, Xu Y, Wang K, Cao B, Xu K: Alleviating effects of silicate, selenium, and microorganism fertilization on lead toxicity in ginger (Zingiber officinale Roscoe). Plant Physiol Biochem 2019, 145:153-163.

58. Srivastava RK, Pandey P, Rajpoot R, Rani A, Gautam A, Dubey RS: Exogenous application of calcium and silica alleviates cadmium toxicity by suppressing oxidative damage in rice seedlings. PROTOPLASMA 2015, 252(4):959-975.

59. Yin F, Liu X, Cao B, Xu K: Low pH altered salt stress in antioxidant metabolism and nitrogen assimilation in ginger (Zingiber officinale) seedlings. Physiol Plant 2019.

60. Rauckman EJ, Rosen GM, Kitchell BB: Superoxide radical as an intermediate in the oxidation of hydroxylamines by mixed function amine oxidase. MOL PHARMACOL 1979, 15(1):131-137.

61. Gay C, Gebicki JM: A critical evaluation of the effect of sorbitol on the ferric-xylenol orange hydroperoxide assay. ANAL BIOCHEM 2000, 284(2):217-220.

62. Liu C, Guo J, Cui Y, Lü T, Zhang X, Shi G: Effects of cadmium and salicylic acid on growth, spectral reflectance and photosynthesis of castor bean seedlings. PLANT SOIL 2011, 344(1):131-141.

63. Cao B, Ma Q, Xu K: Silicon restrains drought-induced ROS accumulation by promoting energy dissipation in leaves of tomato. PROTOPLASMA 2019.

\section{Tables}

Due to technical limitations, the tables are only available as a download in the supplemental files section.

\section{Figures}


Figure 1

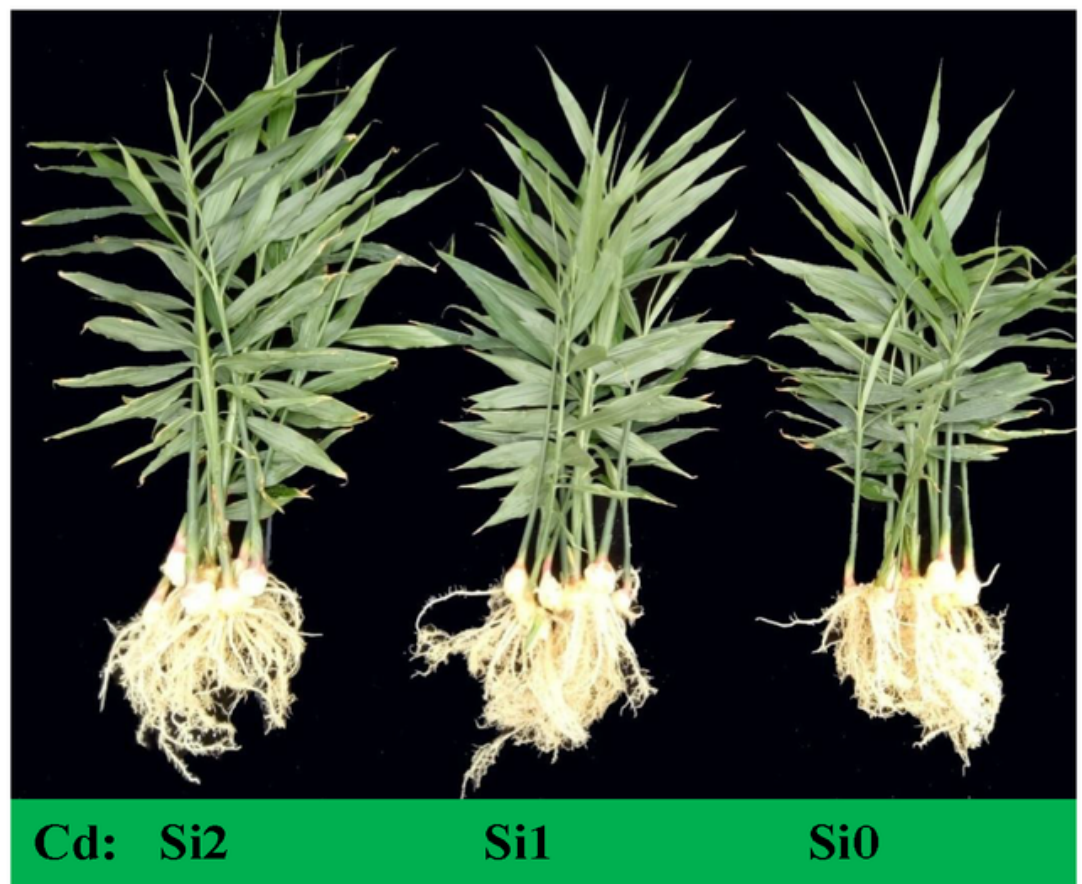

Fig 1.The morphology of ginger at rhizome expansion stage under $\mathrm{Si}, \mathrm{Si} 1, \mathrm{Si} 2$ treatment.

Figure 1

The morphology of ginger at rhizome expansion stage under Si0,Si1,Si2 treatment. 
Figure 2
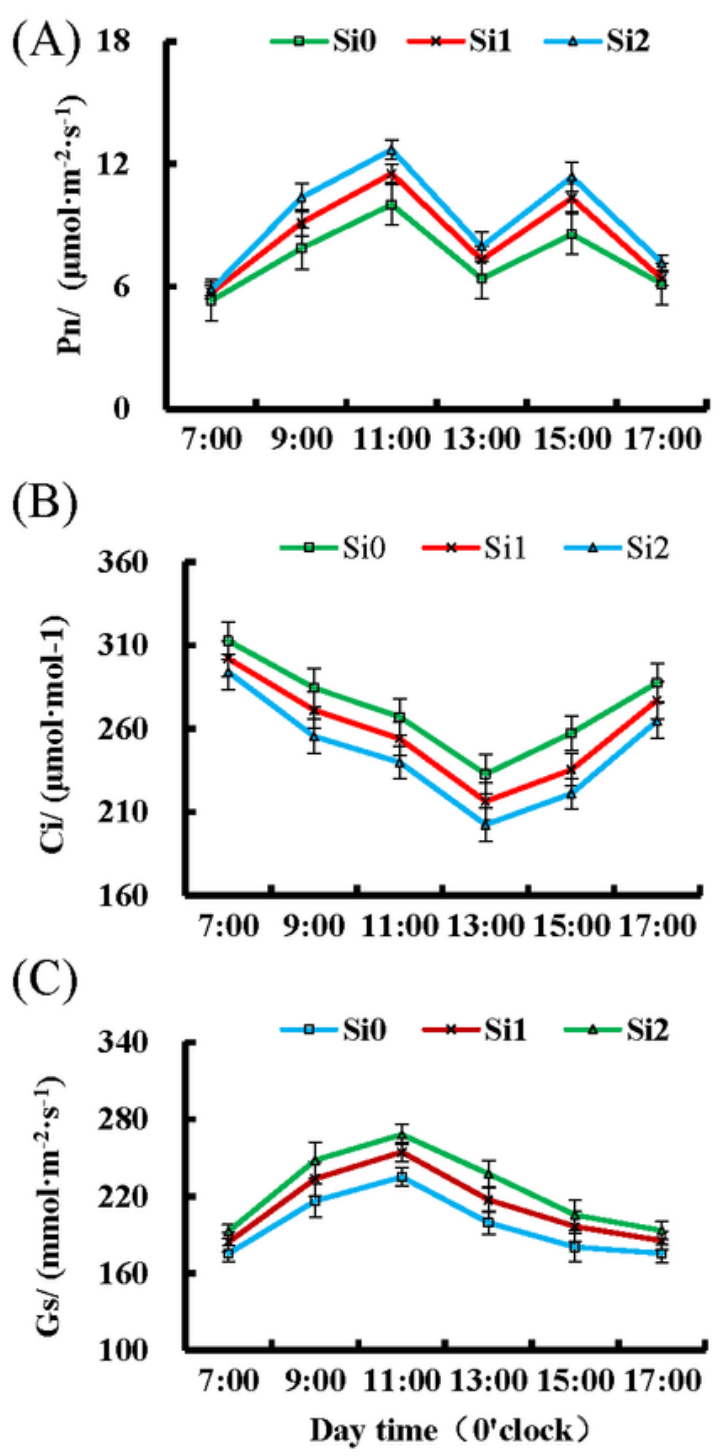

Fig 2.The effect of silicon on diurnal variation of photosynthesis during rhizome expansion stage under Cd stress.(A)Pn of $\mathrm{Sio}, \mathrm{Si} 1, \mathrm{Si}_{2}^{\prime}$ at 7:00,9:00,11:00,13:00,15:00,17:00 in one day.(B)Ci of Sio,Si1,Si2 at 7:00,9:00,11:00,13:00,15:00,17:00 in one day.(C)Gs of Sio,Si1,Si2 at 7:00,9:00,11:00,13:00,15:00,17:00 in one day. Error bars stand for the standard errors.

\section{Figure 2}

The effect of silicon on diurnal variation of photosynthesis during rhizome expansion stage under $\mathrm{Cd}$ stress. (A)Pn of Si0,Si1,Si2 at 7:00,9:00,11:00,13:00,15:00,17:00 in one day.(B)Ci of Sio,Si1,Si2 at 7:00,9:00,11:00,13:00,15:00,17:00 in one day.(C)Gs of Si0,Si1,Si2 at 7:00,9:00,11:00,13:00,15:00,17:00 in one day. Error bars stand for the standard errors. 


\section{Figure 3}

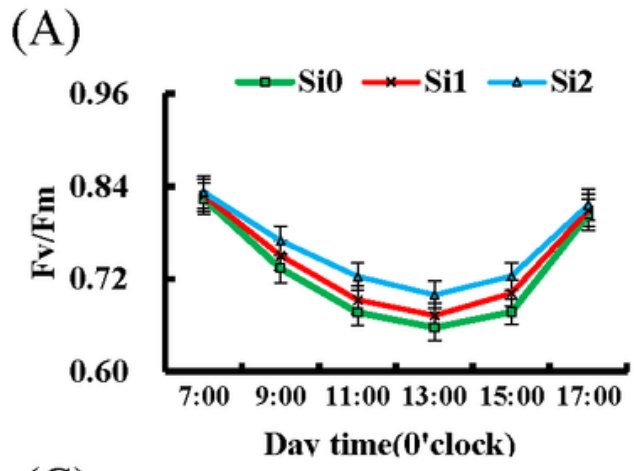

(C)

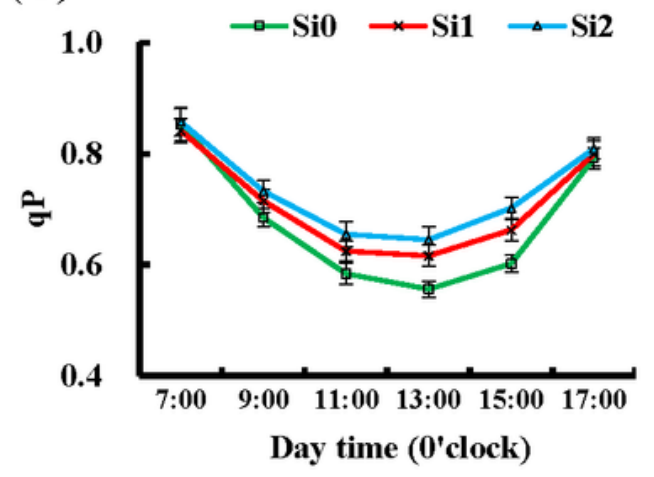

(B)

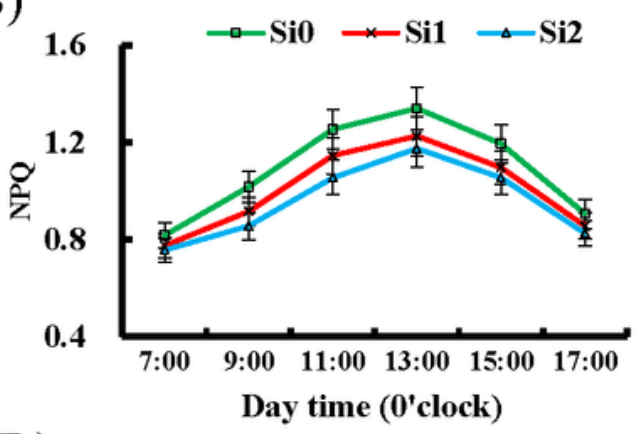

(D)

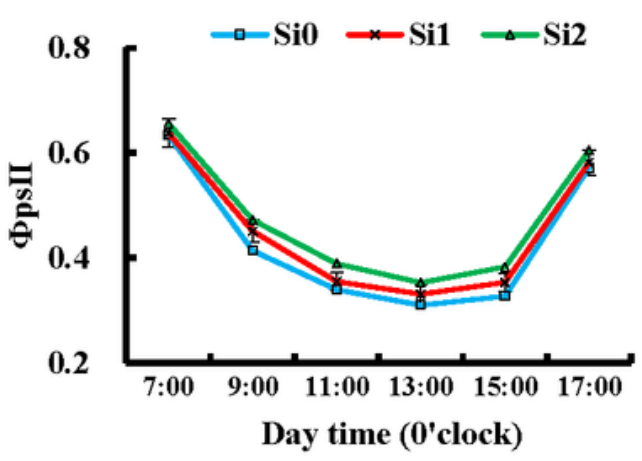

Fig 3.The effect of silicon on the diurnal variation of fluorescence parameters of ginger leaves under $\mathrm{Cd}$ stress. (A)Fv/Fm of $\mathrm{Si} 0, \mathrm{Si} 1, \mathrm{Si} 2$ a 7:00,9:00,11:00,13:00,15:00,17:00 in one day.(B)NPQ of Si0,Si1,Si2 at 7:00,9:00,11:00,13:00,15:00,17:00 in one day.(C)qP of Si0,Si1,Si2 at 7:00,9:00,11:00,13:00,15:00,17:00 in one day.(D) $\Phi$ psII of Si0,Si1,Si2 a 7:00,9:00,11:00,13:00,15:00,17:00 in one day. Error bars stand for the standard errors.

Figure 3

The effect of silicon on the diurnal variation of fluorescence parameters of ginger leaves under Cd stress. (A)Fv/Fm of Si0,Si1,Si2 at 7:00,9:00,11:00,13:00,15:00,17:00 in one day.(B)NPQ of Si0,Si1,Si2 at 7:00,9:00,11:00,13:00,15:00,17:00 in one day.(C)qP of Si0,Si1,Si2 at 7:00,9:00,11:00,13:00,15:00,17:00 in one day.(D) $\Phi p s \rrbracket$ of Si0,Si1,Si2 at 7:00,9:00,11:00,13:00,15:00,17:00 in one day. Error bars stand for the standard errors. 
Figure 4
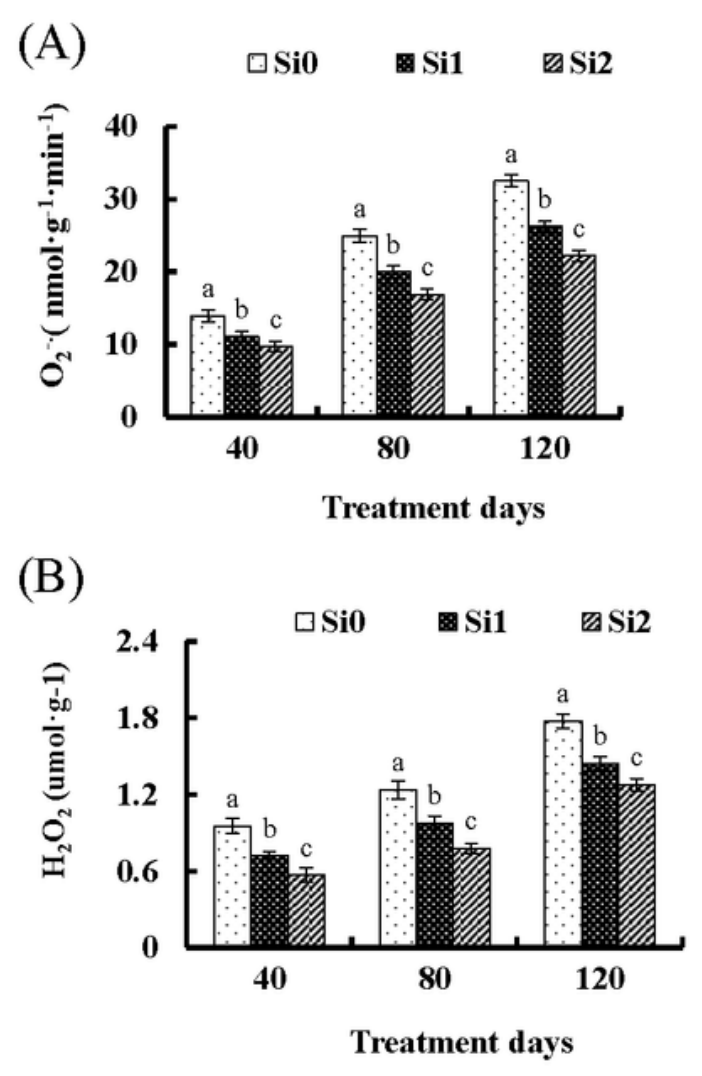

Fig 4.The effect of silicon on the activity level of ginger leaves under $\mathrm{Cd}$ stress.

(A) $\mathrm{O}_{2}^{-\cdot}$ of $\mathrm{Si} 0, \mathrm{Si} 1, \mathrm{Si} 2$ at $40,80,120$ day.(B)H2O 2 of $\mathrm{Si} 0, \mathrm{Si} 1, \mathrm{Si} 2$ at $40,80,120$ day. Values followed with the same letter was not significant at $P=0.05$. Error bars stand for the standard errors.

\section{Figure 4}

The effect of silicon on the activity level of ginger leaves under Cd stress. (A) 02-. of Si0,Si1, Si2 at $40,80,120$ day.(B) $\mathrm{H} 2 \mathrm{O} 2$ of $\mathrm{SiO}, \mathrm{Si}, \mathrm{Si} 2$ at 40,80,120 day. Values followed with the same letter was not significant at $\mathrm{P}=0.05$. Error bars stand for the standard errors. 


\section{Figure 5}

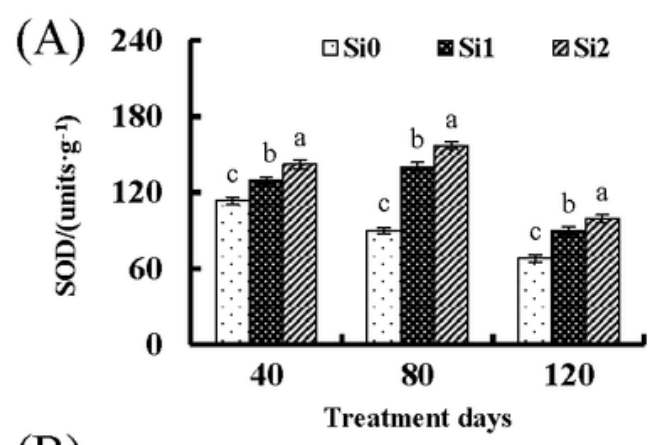

(B)
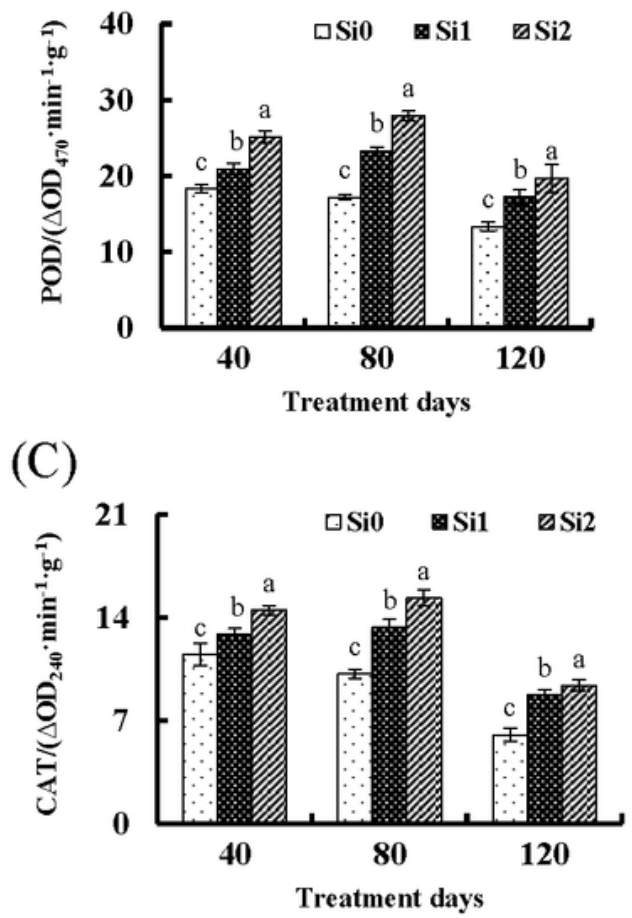

Fig 5.The effect of silicon on antioxidant enzyme activities in ginger leaves under Cd stress.(A)SOD activity of $\mathrm{Si} 0, \mathrm{Si} 1, \mathrm{Si} 2$ at $40,80,120$ day.(B)POD activity of Si0,Si1,Si2 at 40,80,120 day.(C) CAT activity of $\mathrm{Si} 0, \mathrm{Si} 1, \mathrm{Si} 2$ at $40,80,120$ day. Values followed with the same letter was not significant at $P=0.05$. Error bars stand for the

Figure 5

The effect of silicon on antioxidant enzyme activities in ginger leaves under Cd stress. (A)SOD activity of Si0,Si1,Si2 at 40,80,120 day.(B)POD activity of Si0,Si1,Si2 at 40,80,120 day.(C) CAT activity of Si0,Si1,Si2 at $40,80,120$ day. Values followed with the same letter was not significant at $P=0.05$. Error bars stand for the standard errors. 
Figure 6
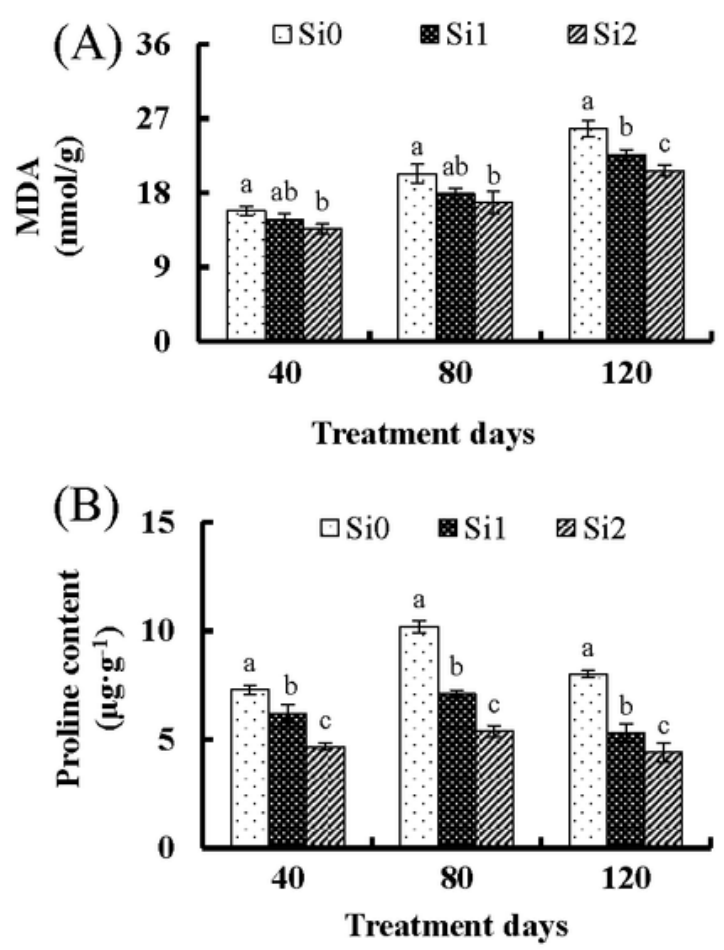

Fig 6. The effect of silicon on the content of MDA and proline in ginger leaves under Cd stress.(A) MDA content of $\mathrm{Si} 0, \mathrm{Si} 1, \mathrm{Si} 2$ at 40,80,120 day. (B)Proline content of Si0,Si1,Si2 at 40,80,120 day. Values followed with the same letter was not significant at $P=0.05$. Error bars stand for the standard errors.

Figure 6

The effect of silicon on the content of MDA and proline in ginger leaves under Cd stress. (A) MDA content of Si0,Si1,Si2 at 40,80,120 day.(B)Proline content of Si0,Si1,Si2 at 40,80,120 day. Values followed with the same letter was not significant at $P=0.05$. Error bars stand for the standard errors.

\section{Supplementary Files}


This is a list of supplementary files associated with this preprint. Click to download.

- Tables.pdf 